\title{
N-MEthylglucamine ANTIMONATE (SbV+): INTRALESIONAL CANINE TEGUMENTARY LEISHMANIASIS THERAPY
}

\author{
BARBOSA SANTOS E.G.O.*, MARZOCHI M.C.A.*, \\ CONCEIÇÃO N.F.*, BRITO C.M.M.*, BARROSO J.A.** \& PACHECO R.S.* ${ }^{*}{ }^{* * *}$
}

\section{Summary :}

Twenty five adult dogs of three municipalities of the State of Rio de Janeiro, Brazil, that had been naturally infected by L. (V) braziliensis were treated with $\mathrm{N}$-methylglucamine antimonate (Glucantime®). Nine of the animals (36.0\%) presented ulcerated skin lesions, twelve $(48.0 \%$ ) had mucosal lesions and four $(16.0 \%$ ) had multiple lesions. In some cases the mucosal lesions were associated to skin lesions. A dose of $85 \mathrm{mg} \mathrm{Sb}^{\mathrm{V}+}$ or $1 \mathrm{ml}$ of the drug was intralesionally administered to the dogs. The animals were divided into three groups according to the amount of necessary doses (between one and three) for the complete healing of the lesions. The dogs were observed for six months after the third group received the last dose. Within this period two animals perished. Serial antibody evaluation through IFAT has shown that in 14 samples $(63.3 \%)$ the titers have remained unaltered, in four of them $(16 \%)$ there has been a decrease in two titers and in five of them $(21 \%)$ serology was negative. Nineteen of the dogs $(86.6 \%)$ had their lesions completely healed. The authors suggest intralesional therapy be the first choice of treatment of canine tegumentary leishmaniasis due to its effectiveness.

KEY WORDS : tegumentary leishmaniasis, canine, intralesional therapy, $\mathrm{N}$-methyl glucamine antimonate.
Résumé : THÉRAPIE INTRA-LÉSIONNELLE AVEC L'ANTIMONIATE DE MÉGLUMINE DANS LES CAS DE LEISHMANIOSE TÉGUMENTAIRE CANINE

Vingt-cinq chiens adultes, provenant de trois communes de l'état de Rio de Janeiro et infectés naturellement par L. (V.) braziliensis, ont été traités par l'antimoniate $\left(S b^{V+}\right)$ de méglumine (Glucantime®). Neut de ces animaux (36\%) présentaient des lésions cutanées ulcérées simples, douze (48\%) des lésions des muqueuses, et quatre $(16 \%)$ des lésions multiples. Le médicament a été administré a la dose de $85 \mathrm{mg} \mathrm{Sb} b^{\mathrm{V}}$ ou $7 \mathrm{ml}$, par voie intralésionnelle. Les chiens ont été séparés en trois groupes selon qu'ils aient reçu une, deux ou trois doses respectivement, jusqu'à la cicatrisation des lésions. Les chiens ont été suivis pendant une durée de 6 mois après la dernière injection. Le dosage des anticorps sériques par IFI a montré que sur 14 échantillons $(63,3 \%)$, les titres sont restés inchangés. Sur quatre échantillons $116 \%$, il s'est produit une chute de 2 dilutions. La sérologie s'est négativée pour cinq d'entre eux $(21 \%)$. La cicatrisation complète des lésions a été observée sur 19 chiens (86,6\%). Les auteurs suggèrent que l'injection intra-lésionnelle de Glucantime $₫$ doit être le premier choix dans le traitement de la leishmaniose tégumentaire canine, en raison de son efficacité.

MOTS CLÉS : leishmaniose tégumentaire, chien, thérapie intra-lésionelle, antimoniate de méglumine.

are frequently found infected with $L$. (V.) braziliensis (Alencar, 1959; Falqueto et al., 1984; Vexenat et al., 1986; Aguilar et al., 1989; Yoshida et al., 1990; Passos et al., 1993). Restriction fragment length polymorphisms of kDNA analysis has shown the same genotypic pattern of the parasite circulating in humans and dogs (Pacheco et al., 1986).

The clinical features of canine tegumentary leishmaniasis (CTL) are similar to the ones of the human disease (Pirmez et al., 1988b). Single or multiple skin lesions occur in the form of ulcerations with irregular raised borders. Canine tegumentary leishmaniasis usually shows a high amount of parasites. The lesions tend to heal spontaneously but they recur months later in the same location, mostly during the colder periods (Marzochi, 1992), which accounts for the persistence of Leishmania in the locus.

Leishmania is a mononuclear phagocyte system (MPS) cellular parasite that can induce humoral and cellular immune responses. In the assays involving natural and experimental canine tegumentary leishmaniasis
* Departamento de Ciências Biológicas, Escola Nacional de Saúde Pública, FIOCRUZ.

** Secretaria Municipal de Saúde de Angra dos Reis, Rio de Janeiro, Brazil.

*** Departamento de Bioquímica e Biologia Molecular, Instituto Oswaldo Cruz, FIOCRUZ.

Correspondance: Elizabeth Gloria Barbosa Santos. Dept. Ciências Biológicas, Escola Nacional de Saúde Pública, FIOCRUZ. Rua Leopoldo Bulhões, $1480 / 6^{\circ}$ andar, 21041-210, Rio de Janeiro, RJ, Brazil. Tel/Fax: (021) 564-8985. 
the observed serial antibody titers are relatively low around 1:80 (Coutinho et al., 1985; Maywald et al., 1996) - and the delayed hypersensitivity skin test shows positive (Marzochi \& Barbosa Santos, 1988). Treatment of dogs infected by L. (V.) braziliensis could be an alternative control measure. However the usual drug $\mathrm{N}$-methylglucamine antimonate is inocuous when it is administrated by systemic route (Pirmez et al., 1988a). Oliveira Neto et al. (1997) reported to have been successful in a longitudinal study of the treatment of ATL patients by means of intralesional inoculation with N-methylglucamine antimonate (Glucantime ${ }^{\circledR}$ ). The purpose of the present study was to evaluate the effectiveness of intralesional therapy with Glucantime ${ }^{\circledR}$ in the treatment of canine tegumentary leishmaniasis in a field assay which took place in endemic areas of the state of Rio de Janeiro, Brazil.

\section{MATERIALS AND METHODS}

\section{DoGs}

There have been selected 25 adult mongrel dogs - four females (16.0\%) and 21 males (84.0\%) - that had been naturally infected. Nine (37.5\%) of the animals showed simple cutaneous lesions, four $(16.0 \%)$ had multiple ulcers, six $(24.0 \%)$ of them had mucosal lesions just in the muzzle and six (24.0\%) of them had mucosal lesions associated to cutaneous lesions. The skin lesions were located mainly on the inside and outside of their ears (54.2\%), and in $4.2 \%$ of the cases they were located on the back and/or scrotal bag (12.5\%) (Table I). The animals came from endemic ATL areas of the municipalities of Rio Bonito (2/8.33\%), Paracambi (10/41.67\%) and Angra dos Reis (12/50\%) in the state of Rio de Janeiro.

Canine tegumentary leishmaniasis diagnosis was based on the features of the skin lesions, on the observation of Leishmania in the material that was taken from the lesions or on its isolation and on positive serology and intradermoreactions.

\section{Parasite Diagnosis}

An in print of the suspicious lesions of all the animals was performed for biopsis, and was followed by Giemsa staining or by vaccum aspirative punction with culture media-filled tubes for the isolation of Leishmania, as described by Marzochi et al. (1993). The

\begin{tabular}{cccc}
\hline $\begin{array}{c}\text { Type/location } \\
\text { of lesions }\end{array}$ & $\begin{array}{c}\text { Amount } \\
\text { of lesions }\end{array}$ & $\begin{array}{c}\text { Amount } \\
\text { of dogs }\end{array}$ & $\begin{array}{c}\text { Amount of dogs/ } \\
\text { doses and results }\end{array}$ \\
\hline $\begin{array}{c}\text { Simple Ulcer } \\
\text { ears } \\
\text { scrootum }\end{array}$ & 6 & 6 & $6 / 1^{\mathrm{C}}$ \\
\hline Sub-total & 3 & 3 & $2 / 2^{\mathrm{C}} ; 1 / 1^{\mathrm{D}}$ \\
\hline $\begin{array}{c}\text { Multiple Ulcers } \\
\text { back } \\
\text { ear }\end{array}$ & 9 & 9 & $6 / 1^{\mathrm{C}} ; 2 / 2^{\mathrm{C}} ; 1 / 1^{\mathrm{D}}$ \\
\hline $\begin{array}{c}\text { ears + scrotum } \\
\text { Sub-total }\end{array}$ & 4 & 1 & $1 / 3^{\mathrm{F}}$ \\
\hline $\begin{array}{c}\text { Simple Mucosal Ulcer } \\
\text { muzzle }\end{array}$ & 4 & 2 & $2 / 1^{\mathrm{C}}$ \\
$\begin{array}{c}\text { Associated Mucosal Ulcer } \\
\text { muzzle + ears }\end{array}$ muzzle + scrotum & 3 & 1 & $1 / 3^{\mathrm{C}}$ \\
\hline $\begin{array}{c}\text { Sub-total } \\
\text { Total }\end{array}$ & 11 & 4 & $1 / 3^{\mathrm{F}} ; 2 / 1^{\mathrm{C}} ; 1 / 3^{\mathrm{C}}$ \\
\hline
\end{tabular}

Symbols: Cure: ${ }^{\mathrm{C}}$; Failure: ${ }^{\mathrm{F}}$; Death: ${ }^{\mathrm{D}}$.

Table I. - Classification of the dogs as to type, location and amount of lesions, amount of necessary intralesional Glucantime ${ }^{\circledR}$ doses, and result. 
medium that was used contained a solid phase of enriched blood agar (NNN) with a liquid phase of a heart and brain infusion (BHI), supplemented with $20 \%$ fetal calf serum and streptomycine $250 \mu \mathrm{g} / \mathrm{ml}$ and 5-fluorocytosine $500 \mu \mathrm{g} / \mathrm{ml}$. The culture was kept at $26{ }^{\circ} \mathrm{C}$ and its content was examined every 5 days.

\section{ENZYME ELECTROPHORESIS}

The samples of Leishmania sp. that were isolated in a culture medium were characterized by means of electrophoretical analysis by isoenzyme, as described by Momen et al. (1985). The parasites were collected in a stationary phase of growth and centrifuged at $700 \mathrm{~g}$, for ten minutes at $4{ }^{\circ} \mathrm{C}$ in a $0,15 \mathrm{M}$-EDTA $0,1 \mathrm{M}$ (SE) salt solution. Biochemical analysis was undertaken on an agarose gel which contained nine enzymes: 6phosphogluconate dehydrogenase (6PGDH E.C.1.1.43), glucose phosphate isomerase (GPI E.C.5.3.1.9), isocitrate dehydrogenase (IDH E.C.1.1.42), glucose-6-phosphate-dehydrogenase (G6PDH E.C.1.1.1.49), malatodehydrogenase (MDH E.C.1.1.37), nucleosidase (NH E.C.3.2.2.1), phosphoglucomutase (PGM E.C.1.4.1.9), peptidase 3 (PEP3 E.C.3.4.11) and proline aminopeptidase (PEP-D E.C.3.4.13.9). The samples of $L$. (V) braziliensis (MHOM/BR/75/M2903) and L. (L) chagasi (MHOM/BR/74/PP75) were used as reference.

\section{SEROLOGiC AND CELlUlar EVALUATION}

The sera that have been collected by means of venous punction were analysed before the treatment and six months after it with the indirect fluorescence antibody test (IFAT), according to Coutinho et al. (1985). The antigen that was used in the reaction had been prepared with a promastigote suspension of a Leishmania sample that was phenotypically similar to L. major (MHOM/BR/76/JOF), which was characterized by Momen et al. (1985). The sera were prepared in serial twofold dilutions of 1:40 in a phosphate buffer saline (PBS $p \mathrm{H} \mathrm{7,2)}$ ). The titers equal to or greater than 1:40 were considered positive.

Cellular immunity was detected before treatment and after blood samples in vivo by means of a skin test with the antigen called IMUNOLEISH, which was prepared with a sample of $L$. (V) braziliensis (Marzochi \& Barbosa Santos, 1988). Each animal received intradermally on the inside of the back limb $0.1 \mathrm{ml}$ of the antigene suspension, which contained $200 \mu \mathrm{g}$ of the total proteine. The reading was done 48 hours later and an induration of $5.0 \mathrm{~mm}$ or more was considered positive.

\section{INTRALESIONAL THERAPY}

The N-methylglucamine antimonate (Glucantime ${ }^{\circledR}$, Rhône-Poulenc Rorer, France) was administered to each skin lesion. A dose of $85 \mathrm{mg} \mathrm{Sb}^{\mathrm{V}+} /$ lesion or 1.0 $\mathrm{ml}$ of a $5.0 \mathrm{ml}$ solution which contained $425 \mathrm{mg} \mathrm{Sb}{ }^{\mathrm{V}+}$ was slowly injected into the cardinal points around each lesion with a $13 \times 4.0$ gauge needle.

The dogs were divided into three groups according to the number of series (up to 3) that had been necessary for the healing of the lesions: nine animals had the need for one dose only (Group 1), two of them received two doses (Group 2) and 11 others received three doses at intervals of twenty days between each series. During the experiment two animals died due to adverse infections.

The criteria that was adopted to define cure was the complete epithelization of the lesions which was checked six months after the treatment.

\section{STATISTICAL ANALYSIS}

The McNemar test for comparison of IFAT observed titers was undertaken before and after the treatment.

\section{RESULTS}

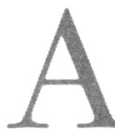

11 ulcerated lesions that were examined were positive for Leishmania. The stained in-prints showed $21(84.0 \%)$ dogs to be positive and it was possible to isolate the parasites by means of the vacuum-closed culture-medium filled tubes (Marzochi et al. 1993) in 19 (86.6 \%) of the cases. Eight samples of Leishmania were analysed through enzyme electrophoresis with the use of nine enzyme loci. All samples presented isoenzymatic profiles that were compatible with $L$. (V) braziliensis (Fig. 1).

In the three observed groups the titers of serial antibodies that were detected before the treatment varied

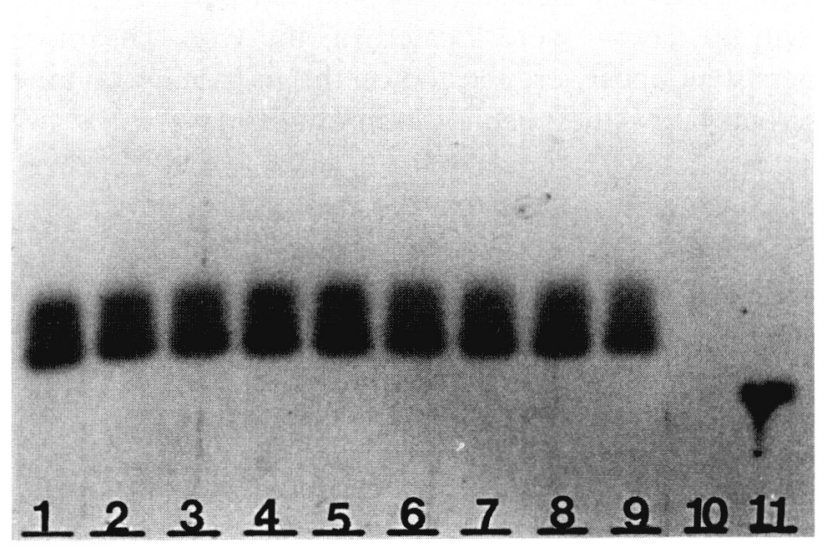

Fig. 1. - Photograph of agarose after staining for G6PDH. Electrophoretic analysis of eight canine skin lesion isolates (1-8). Reference sample of $L$.(V) braziliensis (MHOM/BR/75/2905) (9) and L.(L) chagasi (MHOM/BR/74/PP75) (11). 


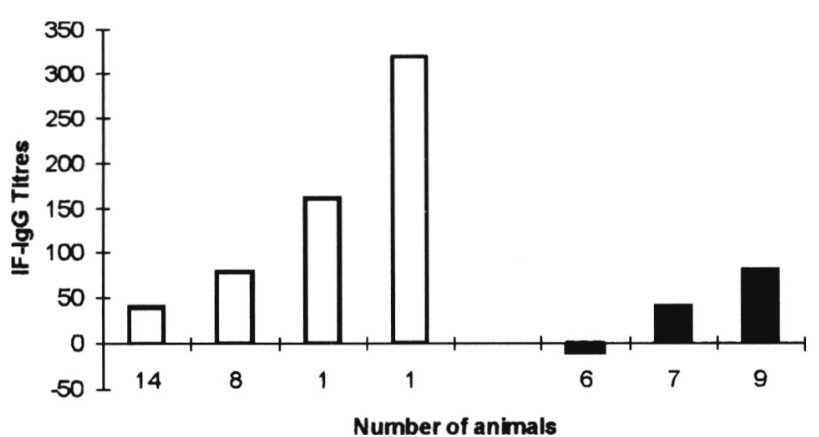

Fig. 2. - Anti-Leishmania serum antibody detected before the treatment $]$ and six months after it $(p \leq 0.005 ; \alpha=0.05)$.

between 1:40 and 1:80 except in two cases in which the encountered titers were $1: 160$ and 1:320. Six months after intralesional therapy the detected serology in 14 dogs (56.0\%) remained positive with no changes in the titers $(\leq 1: 180)$. Four $(16.0 \%)$ animals showed a decrease in two serologic titers and five (20.0\%) showed negative serology (Fig. 2). A statistical difference in serologic titers, that was detected in both periods ( $p \leq 0.005, \alpha=0.05$ ), was observed. Delayed hypersensitivity reactions were positive among all dogs and their diameters were of $8.0 \mathrm{~mm}$ (s.d. = $1.5 \mathrm{~mm}$ )

It was possible to treat every lesion of the 19 (86.6. \%) of the 22 dogs that remained under study. The epithelization of the ulcers was complete and only one residual erithema remained.

The dogs were weekly observed for six months. Within this period it was possible to notice that the animals that had skin lesions on their ears had the need for just one dose of Glucantime ${ }^{\circledR}$ (Group 1). On the other hand, Groups 2 and 3, which had the need for two or three doses of the drug, consisted of dogs that had cutaneous lesions on the muzzle and on the scrotum. The lesions that healed in the shortest period - in less than 30 days - were located on the ears. The more persistent ones were located on the muzzle and on the scrotal bag - they healed in about 60 days.

\section{DISCUSSION}

he aim of this study was to evaluate the effectiveness of canine tegumentary leishmaniasis treatment with intralesional administration of Glucantime ${ }^{\circledR}$. The dogs under study had been naturally infected by $L .(V$.) braziliensis according to the undertaken isoenzymatic characterization. To the moment, this species remains solely responsible for the ATL that is found in Rio de Janeiro (Grimaldi \& Tesh, 1993).
Systemic treatment with antimonials has given inconsistent results on canine leishmaniasis (Marzochi et al., 1985; Pirmez et al., 1988a). The intralesional treatment of human cutaneous leishmaniasis was acknowledged by WHO (1990) which recommended its use. The obtained results have shown that it was possible to treat canine tegumentary leishmaniasis with Glucantime ${ }^{\circledR}$ by intralesional $\mathrm{N}$-methylglucamine antimonate. The rate of clinical cure six months after the treatment was of $86.6 \%$. Pirmez et al. (1988a), in a similar experiment in which they administered the same drug intramuscularly, obtained $80.9 \%$ of cure after three months with $42.8 \%$ of resurgence at the period of five months.

Serological reactions are auxiliary instruments for the diagnosis and the observation of the treatment of infectious diseases. Positive serial titers after antimonial tegumentary leishmaniasis therapy might anticipate the upsurge of secondary lesions in the future. However, in most of human cases, there has been observed a decrease in the IFAT detected serological levels that reach negative results and that show no metastatic oral and nasal mucosae lesions (Mendonça et al., 1988).

As to the results obtained in the IFAT of the dogs' serial samples after treatment, it has been observed that, although most of them $(14 / 62.7 \%)$ kept the previous titers - and this includes the ones that have not been cured $-4(16,0 \%)$ of them showed a decrease of two serological titers and in $5(21 \%)$ of them serology was negative. With regard to the $4(20 \%)$ dogs whose treatment has failed, there is a possibility that renewed doses of Glucantime ${ }^{\circledR}$ might contribute to the disappearance of the lesions and to the decrease of the antibody titers.

In vitro activity of the amastigotes has proved to be a good gauge of in vivo activity for several leishmanicide compounds (Croft, 1986). The evaluation of Glucantime ${ }^{\circledR}$ in canine peritoneal macrophages that have been infected by L.(V) braziliensis, L.(L)amazonensis and L.(L)chagasi was analysed by Madeira et al., 1997 (submitted). The assay has shown pentavalent antimony to be more efficient than Berenil( (aromatic diamidines) in macrophage infections by L.(V.) braziliensis with $\mathrm{LD}_{50}$ equal to $0.5 \mathrm{~g} / \mathrm{ml}$.

The unresponsiveness to antimonial drugs in human visceral and mucocutaneous leishmaniasis is a serious clinical problem (Marsden et al., 1984) and its prevalence appears to be increasing (Marsden, 1985). Intralesional tegumentary leishmaniasis therapy has been administered to human beings with success (Gadelha et al., 1985; Oliveira Neto et al., 1997; Tallab et al., 1996). In the present study, the adequate amounts of intralesionally administrated Glucantime ${ }^{\circledR}$ were apparently able to reach the desired tissue and intracellular 
levels in order to eliminate intracellular parasites with minimal interference with the animal's metabolism. In addition, the amount required by intralesional treatment is low and could prevent the resistance of parasite to antimony as occurs on systemic treatment of dogs with leishmaniasis (Grammiccia et al., 1992). Even though the intralesional inoculation to dogs has been observed over a relatively short period of 6 months, its effectiveness as well as its feasibility may have been demonstrated as long as it is adequately administered. In this sense the treatment of canine tegumentary leishmaniasis, an auxiliary measure that aims at controlling the disease among human beings, might be taken into consideration if we bear in mind that the canine infection is extremely frequent in endemic rural and urban areas and that intralesional antimonial therapy is inexpensive.

\section{ACKNOWLEDGEMENTS}

o Secretaria Municipal de Saúde of Angra dos Reis for the institutional support given during the field studies in that region.

Financial support: this research has been supported by FIOCRUZ (Brazil).

\section{REFERENCES}

Aguilar C.M., Rangel E.F., Fernandez E., Momen H. \& GriMALDI Jr G. Zoonotic cutaneous leishmanisis due to Leishmania (Viannia) braziliensis associated with domestic animals in Venezuela and Brazil. Memorias do Instituto Oswaldo Cruz, 1989, 84, 19-28.

AlENCAR J.E. Um caso de leshmaniose tegumentar em Equus asinus. XIV Congresso Brasileiro de Higiene, 1959, Niterói, Brasil.

Coutinho S.G., Nunes M.P., Marzochia M.C.A. \& TramonTINO N. A survey for American cutaneous leishmaniasis and visceral leishmaniasis among 1342 dogs from areas in Municipality of Rio de Janeiro (Brazil) where the human disease occurs. Memorias do Instituto Oswaldo Cruz, 1985, $80,7-2$.

Croft S.L. In vitro screens in the experimental chemotherapy of leishmaniasis and trypanosomiasis. Parasitology Today, 1986, 2, 64-69.

Falqueto A., Coura J.R., Barros G.C., Grimaldi Jr G., Sessa P.A., Carias V.D.R. \& Jesus A.C. Participação do cão no ciclo de transmissão da leishmaniose tegumentar no Município de Vianna, Estado do Espírito Santo, Brasil. Memorias do Instituto Oswaldo Cruz, 1984, 81, 153-163.

Gadelha A.R., Oliveira W.C. \& Assunção I.J. Tratamento da leishmaniose tegumentar americana com injeções intralesionais de n-metil glucamina. Anais Brasileiros de Dermatologia, 1995, 65, 201-203.
Gramiccia M., Gradoni L. \& Orsini S. Decrease sensitivity to meglumine antimoniate (Glucantime) of Leishmania infantum isolated from dogs after several courses of drug treatment. Annals of Tropical Medicine and Parasitology, 1992, 86, 613-620.

Grimaldi Jr G.\& Tesh R.B. Leishmaniases of the New world: Current concepts and implications for future research. Clinical of Microbiology Rewiew, 1993, 6, 230-250.

Madeira M.F., Barbosa Santos E.G.O. \& Marzochi M.C.A. Experimental treatment of leishmaniasis. An in vitro study in canine macrophage culture. Annals of Ttropical Medicine \& Parasitology (submitted).

Marsden P.D. Pentavalent antimonials: old drugs for new diseases. Revista da Sociedade Brasileira de Medicina Tropical, 1985, 187-198.

Marsden P.D., Llanos-Cuentas E.A., Lago E.I., Cuba C.C., BarReto A.C., Costa J.M. \& Jones T.C. Human mucocutaneous leishmaniasis in Tres Braços, Bahia-Brazil: an area of Leishmania braziliensis braziliensis transmission. III. Mucosal disease: Presentation and initial evolution. Revista da Sociedade Brasileira de Medicina Tropical, 1984, 17, 179-186.

Marzochi M.C.A., Coutinho S.G., Souza W.J.S., Toledo L. M., Grimaldi Jr. G., Momen H., Pacheco R.S., Sabroza P. C., Souza M.S., Rangel Jr. F.B. \& Tramontano N.C. Canine visceral leishmaniasis in Rio de Janeiro, Brazil. Clinical, parasitological, therapeutical and epidemiological findings (1977-1983). Memorias do Instituto Oswaldo Cruz, 1985 , $80,349-357$.

Marzochi M.C.A. \& Barbosa Santos E.G.O. Evaluation of a skin test on the diagnosis of canine leishmaniasis. Memorias do Instituto Oswaldo Cruz, 1988, 83, 391-392.

Marzochi M.C.A. As leishmanioses no Brasil. Jornal Brasileiro de Medicina, 1992, 63, 82-104.

Marzochi M.C.A., TeIXeIra P.C., Marzochi K.B.F., ConceiÇÃo N.F., Coutinho W. \& BRITO D.B. Vacuum aspiratory puncture system for Leishmania culturing, isolation and transport. Preliminary report. Revista do Instituto de Medicina tropical de São Paulo, 1993, 35, 301-303.

Marzochi M.C.A. \& Marzochi K.F.B. Tegumentary and visceral leishmaniases in Brazil - Emerging anthropozoonosis and possibilities for their control. Cadernos de Saúde Pública do Rio de Janeiro, 1994, 10, 359-375.

Maywald P.G., Machado M.I., Costa Cruz S.M. \& Gonçalves PIRES M.R.F. Leishmaniose tegumentar, visceral e doença de Chagas caninas em Municipios do Triângulo Mineiro e Alto Paranaíba, MG, Brasil. Cadernos de Saude Publica do Rio de Janeiro, 1996, 12, 321-328.

Mendonça C.F.S., Souza J.S., Nunes M.P., Marzochi M.C.A. \& CoutinHo S.G. Indirect immunofluorescence test in new world leishmaniasis: serological and clinical relationship. Memorias do Instituto Oswaldo Cruz, 1988, 83, 347-355.

Momen H., Grimaldi Jr. G., Pacheco R.S., Jaffe C. L.L., MCMAHON-Pratt D. \& Marzochi M.C.A. Brazillian Leishmania stocks phenotypic similar to Leishmania major. American Journal of Tropical Medicine and Hygiene, 1985, 34, 1076-1084. 
Oliveira Neto M.P., Schubach A., Mattos M., Gonçalves Da Costa S.C. \& Pirmez C. Intralesional therapy of American cutaneous leishmaniasis with pentavalent antimony in Rio de Janeiro, Brazil - an area of Leishmania (V.) braziliensis transmission. International Journal of Dematology, 1997, 36, 463-468.

Pacheco R.S., Lopes U.G., Morel C.M., Grimaldi Jr G. \& Momen H. Schizodeme analysis of Leishmania isolates and comparison with some phenotypic techniques. In: Leishmania taxonomie et phylogénèse. Applications Eco-épidémiologiques IMEEE, Montpellier, 1986, p. 57-65.

Passos V.M.A., Falcão A.L., Marzochi M.C.A., Contuo C.M.F., Dias E.S., Barbosa Santos E.G.O., Guerra H.L. \& Katz N. Epidemiological aspects of American cutaneous leishmaniasis in a periurban area of the metropilitan region of Belo Horizonte, Minas Gerais State. Memorias do Instituto Oswaldo Cruz, 1993, 28, 103-107.

Pirmez C., Coutinho S.G., Marzochi M.C.A., Nunes M. \& GriMALDI Jr. G. Canine American cutaneous leishmaniasis: a clinical and immunological study in dogs naturally infected with Leishmania braziliensis braziliensis in an endemic area of Rio de Janeiro, Brazil. American Journal of Tropical Medicine and Hygiene, 1988a, 38, 52-58.

Pirmez C., Marzochi M.C.A. \& Coutinho S.G. Experimental canine mucocutaneous leishmaniasis (Leishmania braziliesis braziliensis). Memorias do Instituto Oswaldo Cruz, 1988b, 83, 145-151.

Tallab T.M., Bahamdam K.A., Mirad S., Johargi H., Mourad M.M., Ibrahim K., El Sherbini A.H., Karkashan E., Khare A.K. \& Jamal A. Cutaneous leishmaniasis: schedules for intralesional treatment with sodium stibogluconate. International :Journal of Dermatology, 1996, 35, 594-597.

Vexenat T.A., Barreto A.C., Rosa A.C., Salles C.C. \& MaGALHÃES V. Infecção natural de Equus asinus por Leishmania b. braziliensis, Bahia. Memorias do Instituto Oswaldo Cruz, 1986, 81, 237-238.

Yoshida E.L., Correa F.M., Marques S.A., Stolf H.O., Dillon N.L., Momen H. \& Grimaldi Jr. G. Human, canine and equine (Equus caballus) leishmaniasis due to Leishmania braziliensis (Leishmania braziliensis braziliensis) in the south-west region of São Paulo, Brazil. Memorias do Instituto Oswaldo Cruz, 1990, 81, 237-238.

WHO. Control of leishmaniasis. WHO Technology Report Series, 1990, 793, 53.

Reçu le 20 août 1997 Accepté le 9 décembre 1997 